\title{
Successful Models of Hackathons and Innovation Contests to Crowdsource Rapid Responses to COVID-19
}

\author{
KIEV GAMA, Centro de Informática, Universidade Federal de Pernambuco (UFPE), Brazil
}

\begin{abstract}
To help fighting the many adversarial effects that the COVID-19 pandemic brought, many initiatives supported by public, private and non-governmental organizations are crowdsourcing the development of solutions through hackathons and innovation contests. This article discusses the models and common aspects of two successful initiatives led by governmental institutions that used a crowdsourcing approach to foster solutions aiming at pandemic-related issues: the EUVsVirus (Europe) and the MPLabs COVID-19 Challenge (Brazil).
\end{abstract}

CCS Concepts: • Human-centered computing $\rightarrow$ Computer supported cooperative work;

Additional Key Words and Phrases: COVID-19, open innovation, crowdsourcing, innovation contests, online hackathons

ACM Reference format:

Kiev Gama. 2020. Successful Models of Hackathons and Innovation Contests to Crowdsource Rapid Responses to COVID-19. Digit. Gov.: Res. Pract. 2, 2, Article 20 (December 2020), 7 pages.

https://doi.org/10.1145/3431806

\section{INTRODUCTION}

The COVID-19 pandemic, caused by the virus known as SARS-CoV-2 [21], has confronted the world with an unprecedented situation. In addition to the unrepairable losses of the hundreds of thousands of deaths so far, the coronavirus also brought social and economic impacts on the whole world. This crisis quickly took over the planet, demanding extraordinarily quick responses to contain the spread of the disease and to minimize its impacts. Several initiatives supported by public, private, and non-governmental organizations were put into place using a crowdsourcing approach-where a task or challenge is assigned to a "crowd" and the best solutions are selected. This strategy, taking the form of hackathons and innovation contests, is being used worldwide to foster the fast development of solutions to combat the coronavirus pandemic. These two types of contests have subtle differences, such as the duration and location: Innovation contests are typically online and with a longer duration (weeks or months) than hackathons, which are in-person events that usually take place over a weekend. In addition, hackathon participants are mostly centered around a software deliverable while innovation contests are broader in what the deliverable can be (e.g., an idea, a concept, a process, a product prototype). Innovation contests grew in popularity in the 2000s in the corporate world as tools for new ideas [1], while hackathons,

The author acknowledges partial support from the Brazilian National Council for Scientific and Technological Development (CNPq), Grant No. 315620/2018-8.

Author's address: K. Gama, Centro de Informática, Universidade Federal de Pernambuco (UFPE), Recife, Av. Jornalista Anibal Fernandes, S/N, Cidade Universitária - CEP 50740-560, Brazil; email: kiev@cin.ufpe.br.

Permission to make digital or hard copies of all or part of this work for personal or classroom use is granted without fee provided that copies are not made or distributed for profit or commercial advantage and that copies bear this notice and the full citation on the first page. Copyrights for components of this work owned by others than ACM must be honored. Abstracting with credit is permitted. To copy otherwise, or republish, to post on servers or to redistribute to lists, requires prior specific permission and/or a fee. Request permissions from permissions@acm.org.

(c) 2020 Association for Computing Machinery.

$2639-0175 / 2020 / 12-A R T 20 \$ 15.00$

https://doi.org/10.1145/3431806

Digital Government: Research and Practice, Vol. 2, No. 2, Article 20. Publication date: December 2020. 
which consist of teams working together during 2 to 3 days to develop software prototypes to tackle a specific problem [14], became popular in the 2010s.

Many COVID-19-motivated events of both types are being organized worldwide since the beginning of the pandemic. Due to the many lockdown and curfew measures that were put into practice in many places around the world, hackathons during the pandemic had to move online and teams had to work remotely. Thus, the format of hackathons (now online) and innovation contests became closer. Companies that have been already doing hackathons and innovation contests regularly as a form of branding just adapted their budgets and sponsoring of innovation challenges and hackathons to fit pandemic-related demands. There are also similar initiatives from different sectors that were originated with the sole purpose of quickly generating solutions to this new crisis. However, a common aspect of many of these efforts is that prizes are being awarded to the best prototypes and ideas but no plan on continuation or support to the winning projects is provided.

The stakes have been high on these strategies for the crowdsourcing of solutions to fight the effects of COVID-19, but these approaches are no silver bullet and have limitations that need to be addressed to become successful initiatives. Innovation contests in the form of "app contests" were seen as an opportunity for a new form of procurement where governments invested in crowdsourced software, but the success and quality of the outcomes were questionable [12]. In the particular case of hackathons, the outcomes typically are functioning prototypes demonstrating an idea. One should not expect a shippable product during a 2 to 3 days hackathon, since transforming them into a ready-to-use product requires many follow-up activities [15]. This was also confirmed from personal experience in the organization of over 30 hackathons and innovation contests, where the winning projects that continued counted on the involvement of sponsors or stakeholders.

In this article, we discuss the models and common aspects of two successful initiatives led by governmental institutions that used a crowdsourcing approach to foster solutions aiming at minimizing impacts of pandemicrelated problems: the EUVsVirus ${ }^{1}$ hackathon and matchathon; and the MPLabs COVID-19 Challenge. ${ }^{2}$

\section{OVERVIEW OF INITIATIVES}

These two initiatives were chosen mainly for two reasons: (1) convenience and (2) the difference in scale. The convenience aspect concerns the high availability of detailed information that can be found on the Internet regarding the EUVsVirus, while in the MPLabs Challenge, in addition to such details available online, we had easy access to organizers allowing to have semi-structured interviews with them. The aspect concerning the difference in scale is that these two initiatives rolled out on different levels: the EUVsVirus was a hackathon at the continental level (pan-European) and the MPLabs COVID-19 challenge was an innovation contest at regional level (state of Pernambuco, Brazil).

\subsection{EUVsVirus Hackathon and Matchathon}

The European Commission, in collaboration with EU member states, hosted a pan-European online hackathon from April 24 to 26, 2020, to connect civil society, innovators, partners, and buyers across Europe to develop innovative solutions to coronavirus-related challenges. There were six general challenge domains: health \& life, business continuity, social \& political cohesion, remote working \& education, digital finance, and a broader category labelled as "other." The winning solutions were selected by a jury and cash prizes were offered by partners to winners of their choosing. The top 120 projects went through another phase called "matchathon," from May 22 to 25, 2020, for online matchmaking between winners, partners, end-users, such as hospitals, and potential investors (venture capitalists, foundations, etc).

According to the event's final report [9], the hackathon was a world record with more than 21,000 participants in 3,500 teams from many nationalities. The best 120 teams went to the matchathon phase, where 458

\footnotetext{
${ }^{1}$ https://www.euvsvirus.org/.

${ }^{2}$ https://desafiocovid19.mppe.mp.br/.

Digital Government: Research and Practice, Vol. 2, No. 2, Article 20. Publication date: December 2020.
} 
supportive partners and investors from public and private sectors went through meetings to match with the best ideas and establish partnerships and funding opportunities for the continuation of the projects. According to organizers, it consisted of the largest online world's matchmaking marathon with 1,500 curated meetings and 2,235 partnerships generated.

This whole initiative made possible the creation of many projects, from connected devices to software-based platforms such as 3D glasses to monitor vital signs and an online matching system for health equipment [16]. The former is a solution consisting of 3D-printed glasses with an embedded monitoring system for COVID-19 patients that continuously monitors their vital signs and gives healthcare professionals faster, more accurate data on the progress of the patient's condition. The latter is a real-time platform that connects healthcare providers with suppliers of personal protective equipment (PPE) and medical devices, aiming to minimize the critical gap between supply and demand and avoid shortages of equipment. The solutions are gradually being deployed and the support of the partnerships was key for those projects to reach a production phase.

\subsection{MPLabs COVID-19 Challenge}

The COVID-19 Challenge is an initiative carried out by the Public Attorney's Office (Ministério Público de Pernambuco (MPPE)) and the Open Innovation Laboratory of the Porto Digital Management Unit (Núcleo de Gestão do Porto Digital (NGPD)), which is a private nonprofit organization responsible for running the Porto Digital technological park ${ }^{3}$ in the city of Recife, Pernambuco state, Brazil. The challenge had the sponsorship of the Health Department of the State of Pernambuco and was conducted within the MPPE's open innovation initiative called MPLabs-initially conceived in a partnership between MPPE and NGPD to bring innovative solutions to tackle MPPE's challenges, which are centered around a wide array of responsibilities such as defending social interests, protection of civil rights, public and cultural heritage protection, fraud investigation, and so on. Due to the unprecedented situation, the MPPE acted slightly outside of their domain and used their innovation framework to spur this challenge seeking to minimize the impacts of the SARS-CoV2 Coronavirus pandemic across the state of Pernambuco and potentially in the whole country.

The objective was creating solutions for the pandemic that could be implemented in the very short term. The desired impact was to reduce the speed of contagion, aiming to avoid saturating the operational capacity of the health system, as well as minimizing the impact of virus transmission. There were five specific challenges: risk groups monitoring, information flow management, social isolation monitoring, support to health agents, and test and diagnosis. For this contest, a total of 543 ideas were submitted, of which 71 were pre-selected and 8 of them were chosen and developed.

The initiative was a very quick response to the arrival of the disease in the state of Pernambuco. The challenge was announced on March 17, 2020, and selection phase took place from March 17 to 20. As a comparison, the first COVID-19 case in Pernambuco was identified on March 12, 2020, universities and schools were closed on the March 18 and non-essential businesses were closed on March 20.

The MPLabs, in partnership with the tech parks' management unit (NGPD), had an open innovation process that was already used in other initiatives. However, it had to be tailored to this emergency situation so the realization of the COVID-19 challenge could be feasible in a short timespan. The original process was shortened from 6 months to 6 weeks. It initially consisted of three phases: (1) challenges; (2) prototyping; and (2) construction of a minimum viable product (MVP). The adaptation made for the COVID-19 challenge eliminated the prototyping phase and simplified the MVP phase that usually takes 3 months and involves many interactions with specialists. There is a preliminary phase for problem immersion and problem identification, which was done in less than a week with the Health Department, originating a sort of structured architecture of needs that guided the call for projects that was publicly announced. Then, two stages followed: (1) Project proposals were submitted and quickly evaluated if they would be approved for the MVP phase, and (2) MVP development and presentation;

\footnotetext{
${ }^{3}$ https://www.portodigital.org/home.
}

Digital Government: Research and Practice, Vol. 2, No. 2, Article 20. Publication date: December 2020 
followed by the MPPE's decision to accelerate the project or not. All eight projects that went to the MVP phase were selected to be financed through this initiative with all of them being quickly deployed and already bringing positive impacts.

Two examples of projects were DyCovid [17] and the Social Isolation Index tool [8]. Both solutions rely on user location tracing strategies widely used in COVID-19 initiatives worldwide that, although useful, have raised concerns around privacy and security implications $[2,6,7]$. These two projects were made available to the public at the end of April 2020, less than two months after the call for projects was announced. Dynamic Covid Tracing (DyCovid) is a contact tracing application targeting Android and iOS phones. By associating information from health entities with location data and the information of other users that are infected, it can infer the app user's risk of infection. Users of this app identified with such risk were prioritized by the Municipal Department of Health in getting tested for the SARS-CoV-2 virus. The Social Isolation Index project was developed by a local startup focused on location-based advertisement. Their solution to the COVID-19 challenge calculates the cities and state level of social isolation based on location data collected from partner apps, without identifying their users. They created dashboards that are being used by the department responsible for public safety and security and also used by the City Hall as a whole. The index was essential for the city administrators to prepare and plan the strategy for gradually reopening businesses when COVID-19 infection rates started to stabilize early in the second semester of 2020 .

\section{LESSONS LEARNED FROM THE TWO CASES}

Innovations aiming at COVID-19 impacts are basically being supported by donations and subsidies, with possible revenue models that are similar to those from social entrepreneurship [18]. However, before reaching that state, we need to think ahead on how to put into place successful initiatives that can foster projects addressing real needs, that can be connected to stakeholders and put into operation fast. We enumerated six common and important aspects as the main lessons learned in those two models of innovation contests we discussed: stakeholder involvement; challenge scope; mentoring; articulation with innovation ecosystem; follow-up; funding; and communication of results.

Stakeholder involvement. Thinking of solutions without validation by stakeholders leads to solutions that solves nobody's problem and that no one will use. Participants tend to build a prototype based on their perceived need rather than accessing marketing information [11]. To avoid that, connections with stakeholders can help in the construction of systems that meet the needs of the clients and have a higher chance to continue after these events [4]. Thus, either in the beginning or during the process stakeholders must be involved, since they are the ones who know what is important to be provided and they are also capable of validating the solutions. The MPLabs challenge relied on the participation of the regional Health Department representatives who were involved since the beginning and helped define what were the main goals and the EUvsVirus involved stakeholders in the matchathon.

Challenge scope. During the initial preparation phase stakeholders may come up with problems or requests, so it is also important to help narrow down to more specific problems to define the scope of the challenge [3, 20]. It gives a more focused direction to competitors while broader scopes can lead to many types of solutions that may be difficult to find funding or interested parties. In the EUVsVirus model, the challenges were broad, allowing a diverse range of solutions, but the interested parties would be contacted during the matchathon that took place days after the hackathon. In the final report [9], while the average number of reported partnerships made during the matchathon was close to 7 per project, 14 projects had only 1 reported partnership and another 15 projects had none. In the MPLabs challenge, because of early stakeholder involvement, it allowed narrow scope challenges, which resulted in solutions that could quickly go to production, although it was close to a "procurement oriented" approach where the stakeholder demand was clear-with well-defined goals although the solution requirements were not so specific-leaving less space to potentially disruptive solutions.

Digital Government: Research and Practice, Vol. 2, No. 2, Article 20. Publication date: December 2020. 
Mentoring. Good mentoring during the conception of products can help giving better direction to projects. Expert mentors can play effects on prototype development, thus it is important to appropriately communicate mentor expertise to innovation contest participants [19]. In the MPLabs challenge, mentoring was provided by domain specialists such as nurses, medical doctors, health agents, and epidemiologists. The purpose was to provide more details, validate the proposals, and inform if they were feasible. Mentoring in the EUvsVirus was not focused on validating requirements but rather general on diverse areas (business, product management, design, science, technologies) needed in the conception of the solutions.

Articulation with the innovation ecosystem. It is fundamental connecting with ecosystem actors that would help the initiative be successful. The important role of Public Open Innovation intermediaries has already been reported in literature [5]. They are either public or private organizations that are key enablers of open innovation strategies. These intermediaries develop expertise in understanding problems, insights or project ideas from government and connect them with innovators through different supporting activities, which tend to be underestimated, such as outsourcing mediation, organization of events and project execution. In the EUvsVirus model, the governmental agency (European Innovation Council (EIC)) was responsible for the articulation with the innovation ecosystem in Europe, mobilizing stakeholders, venture capitalists, investors, accelerators, and so on. The Porto Digital Management Unit is a private nonprofit association that was the intermediate for the MPPE, acting as major player in articulating with the different actors of the local innovation ecosystem and was key to involve other government stakeholders, to mobilize startups, companies, and people with expertise to participate in the COVID-19 challenge.

Follow-up. Doing follow-up on projects is a major gap in hackathons and innovation challenges, since many initiatives provide either low or no post-contest support [13]. Usually, after winners are announced, many of these contests no longer give any support to projects. The EUvsVirus challenge had a follow-up with the matchathon collaboration, by articulating the continuity of the projects with specialists and partner institutions. The MPLabs did the follow-up through project managers who accompanied the teams during the average 5 weeks that the winning projects went through, while they were being developed. That project management support continued after the projects were deployed.

Funding and Sustainability. This is one of the major challenges with the results of innovation contests. The prizes offered to winners usually are not enough for a whole team. The involvement of potential investors works as an incentive for developers that seek post-contest funding [3]. Projects also need a business model and support from accelerators or incubators, which is typically provided or articulated by Public Open Innovation intermediaries [5]. The EUVsVirus, aiming at project sustainability, articulated connections with sponsors that optionally provided prizes and put the team in contact with venture capitalists, investors and other stakeholders during the matchathon, which resulted in many partnerships for continuing the winning projects. The organization role was that of a mediator. The MPLabs model had public funding for the prizes but the tech park management unit (NGPD) kept providing business mentoring aiming to transform the projects into businesses.

Communication of results. Promoting the products that are developed is also one of the challenges in hackathons and innovation competitions [10]. Like any digital product, the outcomes of hackathon and innovation contests need to build a user base. Campaigns to keep communicating the results of the event can help to attract users and investors. A platform or landing page where the information of the challenges and winners can be searched is important as well as announcements on social networks, press releases, and other kinds of publicity. Both initiatives we presented worked well on such publicity of the initiatives and promotion of the resulting projects, with many different news outlets being reached.

\section{THE ROAD AHEAD}

This article described and compared the models of two initiatives for the crowdsourcing of projects around COVID-19. Both of them were quickly put into practice and helped to originate promising and useful projects.

Digital Government: Research and Practice, Vol. 2, No. 2, Article 20. Publication date: December 2020. 
Although focusing on different geographic scales and aiming at different levels of problems, these two models share common aspects that can be seen as success factors for the initiatives. There may be uncertainty about the future of the individual outcomes from these actions in a post-pandemic world, since the usage of projects will have less or even no purpose once the pandemic is controlled. However, from a broader perspective, the models of these two examples can work as references for mechanisms allowing to accelerate and generate rapid responses to emergencies. By identifying and analyzing effective models that can be replicated or inspire adaptations, the chances of success in other crowdsourcing initiatives for innovation can be increased in these scenarios. Not only in a pandemic condition but emergency situations in different forms and dimensions, such as massive fires, floods, and mudslides, to cite a few, are recurring scenarios these days and need quick actions as well. Government-led initiatives mobilizing public funds to spur innovation in the face of such scenarios have to be very efficient in the usage of resources, since higher risks of project failure are involved in these actions, especially when shorter time frames are involved.

\section{REFERENCES}

[1] Sabrina Adamczyk, Angelika C. Bullinger, and Kathrin M. Möslein. 2012. Innovation contests: A review, classification and outlook. Creat. Innovat. Manage. 21, 4 (2012), 335-360.

[2] Nadeem Ahmed, Regio A. Michelin, Wanli Xue, Sushmita Ruj, Robert Malaney, Salil S. Kanhere, Aruna Seneviratne, Wen Hu, Helge Janicke, and Sanjay K. Jha. 2020. A survey of covid-19 contact tracing apps. IEEE Access 8 (2020), 134577-134601.

[3] Esteve Almirall, Melissa Lee, and Ann Majchrzak. 2014. Open innovation requires integrated competition-community ecosystems: Lessons learned from civic open innovation. Business Horizons 57, 3 (2014), 391-400.

[4] Maria Angelica Medina Angarita and Alexander Nolte. 2020. What do we know about hackathon outcomes and how to support them? A systematic literature review. In Proceedings of the International Conference on Collaboration Technologies and Social Computing. Springer, $50-64$.

[5] Tuba Bakici, Esteve Almirall, and Jonathan Wareham. 2013. The role of public open innovation intermediaries in local government and the public sector. Technol. Anal. Strategic Manage. 25, 3 (2013), 311-327.

[6] Surekha Borra. 2020. COVID-19 apps: Privacy and security concerns. In Intelligent Systems and Methods to Combat Covid-19. Springer, $11-17$.

[7] Hyunghoon Cho, Daphne Ippolito, and Yun William Yu. 2020. Contact tracing mobile apps for COVID-19: Privacy considerations and related trade-offs. Retrieved from https://arXiv:2003.11511.

[8] DP. 2020. MPPE elabora ferramenta para mensurar o nível de isolamento social nas cidades pernambucanas [MPPE develops a tool to measure the level of social isolation in the cities of Pernambuco]. Diario de Pernambuco. Retrieved from https://www.diariodepernambuco. com.br/noticia/vidaurbana/2020/05/mppe-elabora-ferramenta-para-mensurar-o-nivel-de-isolamento-social-nas.html.

[9] EU. 2020. From ideas to solutions an example of solidarity, creativity and hard work. Final Report. Retrieved from https://www.euvsvirus. org/finalreport.pdf.

[10] Sarah Hartmann, Agnes Mainka, and Wolfgang G. Stock. 2016. Opportunities and challenges for civic engagement: A global investigation of innovation competitions. In International fournal of Knowledge Society Research. IGI Global, 1-15.

[11] Anders Hjalmarsson, Paul Johannesson, Gustaf Juell-Skielse, and Daniel Rudmark. 2014. Beyond innovation contests: A framework of barriers to open innovation of digital services. In Proceedings of the 22nd European Conference on Information Systems.

[12] Peter Johnson and Pamela Robinson. 2014. Civic hackathons: Innovation, procurement, or civic engagement? Rev. Policy Res. 31, 4 (2014), 349-357.

[13] Gustaf Juell-Skielse, Elea Juell-Skielse, Anders Hjalmarsson, Paul Johannesson, and Daniel Rudmark. 2014. What happens next? A survey of the afterlife of innovation contests. In Proceedings of the 22nd Conference on Information Systems, Workshop on eGovernment.

[14] Marko Komssi, Danielle Pichlis, Mikko Raatikainen, Klas Kindström, and Janne Järvinen. 2014. What are hackathons for? IEEE Softw. 32, 5 (2014), 60-67.

[15] Alexander Nolte, Ei Pa Pa Pe-Than, Anna Filippova, Christian Bird, Steve Scallen, and James D. Herbsleb. 2018. You hacked and now what? Exploring outcomes of a corporate hackathon. Proc. ACM Hum.-Comput. Interact. 2 (2018), 1-23.

[16] Chris Pate. 2020. Six innovations to tackle coronavirus. Horizon-The EU Research \& Innovation Magazine. Retrieved from https:// horizon-magazine.eu/article/six-innovations-tackle-coronavirus.html\#.

[17] Folha PE. 2020. App feito em Pernambuco calcula e alerta risco de contaminação pelo novo coronavírus [App made in Pernambuco calculates and alerts the risk of contamination by the new coronavirus]. Folha de Pernambuco. Retrieved from https://www.folhape.com. br/noticias/app-feito-em-pernambuco-calcula-e-alerta-risco-de-contaminacao-pelo-no/138986/.

[18] Dirk G. Schroeder. 2020. Turn your Covid-19 solution into a viable business. Harvard Business Review Digital Article. Retrieved from https://hbr.org/2020/07/turn-your-covid-19-solution-into-a-viable-business.

Digital Government: Research and Practice, Vol. 2, No. 2, Article 20. Publication date: December 2020. 
[19] Porya Mohajer Soltani, Kalevi Pessi, Karin Ahlin, and Ida Wernered. 2014. Hackathon: A method for digital innovative success: A comparative descriptive study. In Proceedings of the 8th European Conference on IS Management and Evaluation. 367-373.

[20] Qianli Yuan and Mila Gasco-Hernandez. 2019. Open innovation in the public sector: Creating public value through civic hackathons. Public Manage. Rev. (2019), 1-22.

[21] Jun Zheng. 2020. SARS-CoV-2: An emerging coronavirus that causes a global threat. Int. f. Biol. Sci. 16, 10 (2020), 1678.

Received August 2020; revised October 2020; accepted October 2020 